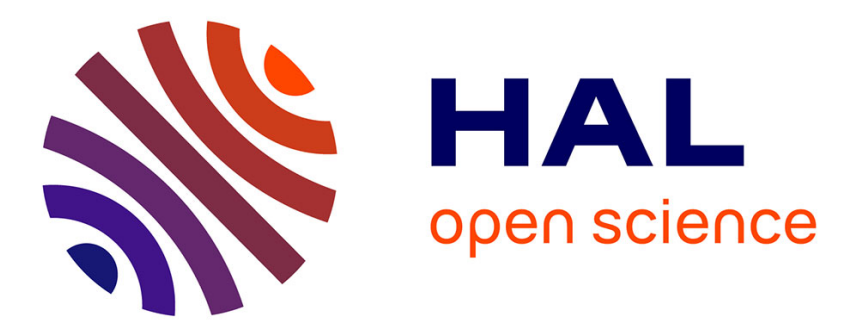

\title{
Unexpected thermo-responsiveness of bisurea-functionalized hydrophilic polymers in water
}

Gaëlle Mellot, Jean-Michel Guigner, Jacques Jestin, Laurent Bouteiller, François Stoffelbach, Jutta Rieger

\section{- To cite this version:}

Gaëlle Mellot, Jean-Michel Guigner, Jacques Jestin, Laurent Bouteiller, François Stoffelbach, et al.. Unexpected thermo-responsiveness of bisurea-functionalized hydrophilic polymers in water. Journal of Colloid and Interface Science, 2021, 581, Part B, pp.874-883. 10.1016/j.jcis.2020.07.147 . hal02917169

\section{HAL Id: hal-02917169 \\ https://hal.science/hal-02917169}

Submitted on 18 Sep 2020

HAL is a multi-disciplinary open access archive for the deposit and dissemination of scientific research documents, whether they are published or not. The documents may come from teaching and research institutions in France or abroad, or from public or private research centers.
L'archive ouverte pluridisciplinaire HAL, est destinée au dépôt et à la diffusion de documents scientifiques de niveau recherche, publiés ou non, émanant des établissements d'enseignement et de recherche français ou étrangers, des laboratoires publics ou privés. 


\section{Unexpected thermo-responsiveness of bisurea- functionalized hydrophilic polymers in water ${ }^{\#}$}

Gaëlle Mellot ${ }^{\dagger}$ Jean-Michel Guigner, ${ }^{\star}$ Jacques Jestin, ${ }^{\S}$ Laurent Bouteiller, ${ }^{\dagger}$ François Stoffelbach ${ }^{\dagger}$ Jutta Rieger ${ }^{\dagger}, *$

${ }^{\dagger}$ Sorbonne Université \& CNRS, Institut Parisien de Chimie Moléculaire, UMR 8232, Equipe Chimie des Polymères, 75252 Paris, France, *E-mail: jutta.rieger@ sorbonne-universite.fr

\$ Sorbonne Université, CNRS, Institut de Minéralogie, de Physique des Matériaux et de Cosmochimie, UMR 7590 - IRD - MNHN, F-75005 Paris, France

§ Laboratoire Léon Brillouin, UMR12 CEA-CNRS, Bât. 563, CEA Saclay, 91191 Gif-surYvette, France

* Corresponding author :

Sorbonne Université \& CNRS, Institut Parisien de Chimie Moléculaire, UMR 8232, Equipe Chimie des Polymères, 4 Place Jussieu, 75252 Paris, France;

Telephone: +0033-(0)144275137; jutta.rieger@ sorbonne-universite.fr

\# This manuscript is in honor of the 50-year anniversary of the French Polymer Group (Groupe Français des Polymères - GFP).

GRAPHICAL ABSTRACT

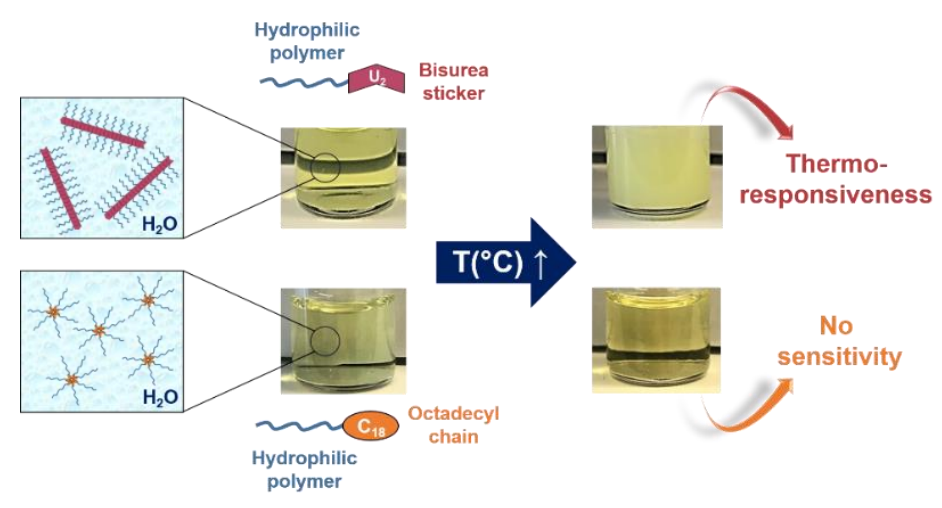

KEYWORDS

Thermoresponsive; LCST; supramacromolecular assemblies; cloud point; nanoDSC; bisurea; cylindrical micelles; supramolecular bottlebrushes; hydrogen bonding 


\section{ABSTRACT}

Hypothesis: Thermoresponsive polymers are important materials for various applications. However, the number of polymers that exhibit this property in the temperature range of interest remains limited. The development of novel rational design strategies through the understanding of the thermal transition's origin is therefore of utmost importance.

Experiments: Bisurea-functionalized water-soluble polymers were synthesized by RAFT polymerization. After direct dissolution in water, the supramolecular assemblies were analyzed by cryoTEM and SANS. Their temperature-dependent water-solubility was characterized by various techniques, namely DLS, SANS, DSC, IR, to understand the origin of the temperature sensitivity.

Findings: The supramolecular assemblies exhibit an unexpected temperature-dependent solubility. For instance, a cloud point of only $39{ }^{\circ} \mathrm{C}$ was measured for $\operatorname{poly}(N, N-$ dimethylacrylamide) assemblies. This property is not restricted to one specific polymer but is rather a general feature of bisurea-functionalized polymers that form supramacromolecular bottlebrushes in water. The results highlight the existence of two distinct transitions; the first one is a visually perceptible cloud point due to the aggregation of individual micelles, presumably driven by the hydrophobic effect. The second transition is related to the dissociation of intermolecular bisurea hydrogen bonds. Finally, we show that it is possible to widely tune the cloud point temperature through the formation of co-assemblies.

\section{INTRODUCTION}

Thermoresponsive polymers have been used to design smart materials as their solutions or gels can exhibit abrupt changes in properties upon temperature variation. They usually exhibit either a lower critical solution temperature (LCST) or an upper critical solution temperature (UCST), which is visually detected as a cloud point (CP). ${ }^{1}$ Polymers that exhibit such features in aqueous solution have been applied in various research fields, for instance as drug delivery systems, cell culture medium, catalyst support, actuator or flocculants. ${ }^{2,3,4}$ For many of these applications, a $\mathrm{CP}$ near body temperature is highly desirable, but the number of homopolymers that exhibit this property in the temperature range of interest is limited. ${ }^{5,6}$ Many synthetic strategies have been devised to tune the properties and to adjust the transition temperature to make them 
suitable for the targeted application. The common strategy to tune the $\mathrm{CP}$ of a water-soluble polymer is to introduce hydrophilic or hydrophobic groups in the structure, either at the chain end yielding semi-telechelic polymers or by copolymerizing the monomer of choice with suitable comonomers. For instance, poly( $N, N$-dimethylacrylamide) (PDMAc), which is watersoluble but not thermoresponsive by itself, exhibits a LCST behavior after being copolymerized with hydrophobic monomers, such as phenyl acrylamide ${ }^{7}$ or styrene. ${ }^{8}$ This strategy has been applied to many polymers, and it generally allows shifting the cloud point over a large temperature range. However, the comonomer may alter the intrinsic properties of the pristine homopolymer, such as biocompatibility. The second strategy relying on end-group functionalization appears to be safer as it does not change the composition of the polymer chain. However, it generally allows tuning the cloud point over a limited temperature range. For instance, the end-functionalization of poly( $N$-isopropylacrylamide) (PNIPAM) by a $n$ octadecyl chain reduces the cloud point by few degrees only. ${ }^{9}$ In contrast, the end-group functionalization of PNIPAM with different monourea groups allowed tuning the cloud point between $29^{\circ} \mathrm{C}$ and $37^{\circ} \mathrm{C} .{ }^{10}$ The authors proposed that the cloud point depression is a direct consequence of the association of the semi-telechelic polymers into micelles or networks, which leads to a higher effective molecular weight than that of the corresponding PNIPAM homopolymer. Inspired by these results, we decided to investigate whether stronger associative stickers can amplify this effect. We selected bisurea stickers that drive the formation of supramolecular polymer bottlebrushes through directional assembly of the sticker by hydrogen bonds. ${ }^{11,12,13}$ The assembly of the polymers in long 1D nanostructures, where the polymer chains are densely packed, might actually alter their solubility properties. ${ }^{14}$ If successful, this strategy could allow converting well-known hydrophilic homopolymers into thermosensitive polymers with a $\mathrm{CP}$ near body temperature, without copolymerization with hydrophobic monomers.

In this study, we used a straightforward strategy ${ }^{12}$ based on RAFT (reversible additionfragmentation chain transfer) polymerizationto synthesize a series of $\alpha$-bisurea-functionalized poly( $N, N$-dimethylacrylamide) (PDMAc), poly(acrylic acid) (PAA), polyacrylamide (PAM), poly(N-4-acryloylmorpholine) (PNAM) and poly(2-hydroxyethylacrylate) (PHEA). The majority of bisurea-functionalized polymers exhibit a cloud point in water at remarkably low temperatures. The origin of this unexpected temperature behavior is elucidated. 


\section{MATERIALS AND METHODS}

\section{Materials}

2,2'-Azobis(isobutyronitrile) (AIBN, $\geq 98 \%$, Aldrich), N,N-dimethylformamide (DMF, VWR, Normapur), acrylic acid (AA, $\geq 99 \%$, Aldrich), acrylamide (AM, $\geq 99 \%$, Aldrich) and 1,3,5trioxane ( $\geq 99 \%$, Aldrich) were used as received. $N, N$-Dimethylacrylamide (DMAc, $>99 \%$, Aldrich) and $\mathrm{N}$-4-acryloylmorpholine (NAM, $\geq 97 \%$, Aldrich) were distilled under vacuum prior to polymerization. 2-Hydroxyethylacrylate (HEA, $\geq 96 \%$, Aldrich) was dissolved in water, washed 10 times with pentane and distilled under vacuum prior to polymerization. All aqueous solutions were prepared with deionized water filtered through a $0.2 \mu \mathrm{m}$ pore-size membrane. All polymerizations were carried out under argon atmosphere.

\section{Synthesis of the bisurea-functionalized and octadecyl-endcapped model polymers}

Bisurea-functionalized PDMAc, PAA, PAM, PNAM and PHEA polymers and octadecylendcapped model polymers were synthetized according to a protocol established before ${ }^{12}$ using a bisurea-functionalized RAFT agent, TTC- $\mathrm{U}_{2}$ or an octadecyl-appended RAFT agent, TTC$\mathrm{C}_{18}$ (Scheme 1A). The detailed experimental conditions are described in Table S1. The polymers were recovered by precipitation in diethyl ether $\left(\mathrm{Et}_{2} \mathrm{O}\right)$ (in chloroform for the PAM or in a mixture of $\mathrm{Et}_{2} \mathrm{O}$ /pentane (1/1 vol.) for PHEA), dried under reduced pressure and characterized by ${ }^{1} \mathrm{H}$ NMR in DMSO-d 6 and SEC in DMF (or in DMSO for PAM) (+ LiBr, $1 \mathrm{~g}$ $\left.\mathrm{L}^{-1}\right)$.

\section{Characterizations.}

The polymers were analyzed by ${ }^{1} \mathrm{H}$ NMR spectroscopy, Size Exclusion Chromatography (SEC) in DMF (+ LiBr, $1 \mathrm{~g} \mathrm{~L}^{-1}$ ) and Differential Scanning Calorimetry (DSC). The supramolecular assemblies in water were analyzed by Dynamic Light Scattering (DLS), Variable Temperature Fourier Transformed InfraRed (VT-FTIR) spectroscopy, Small-Angle Neutron Scattering (SANS), Nano-Differential Scanning Calorimetry (Nano-DSC) and Cryogenic Transmission Electron Microscopy (cryoTEM). Details are reported in the Supporting Material. 


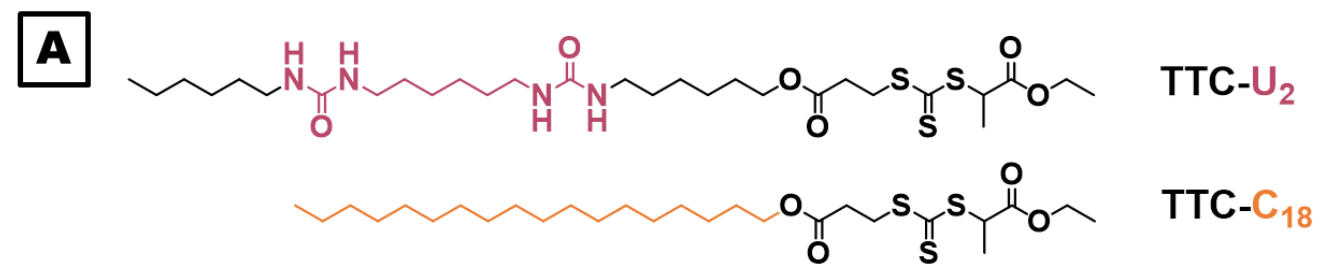

B
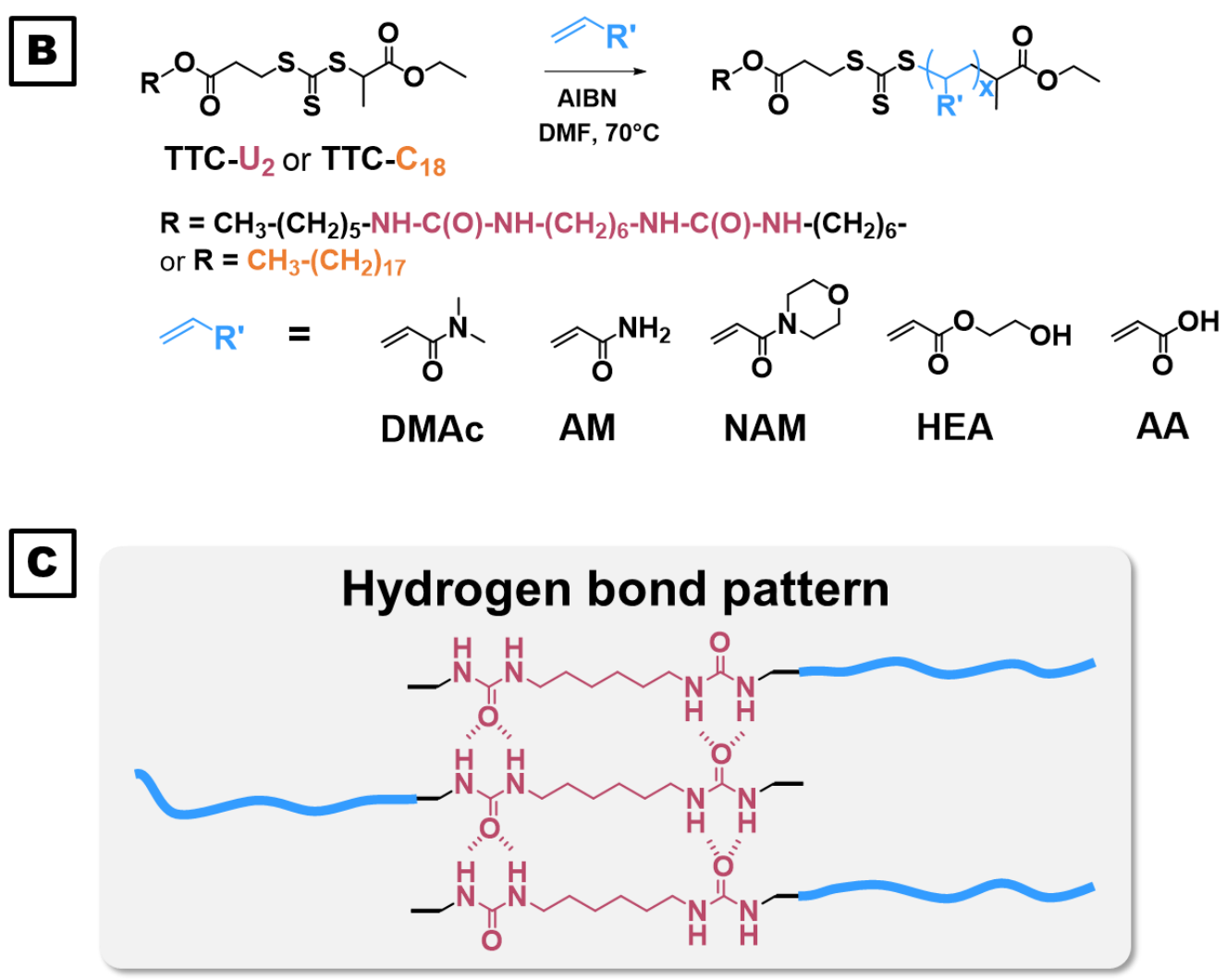

with :

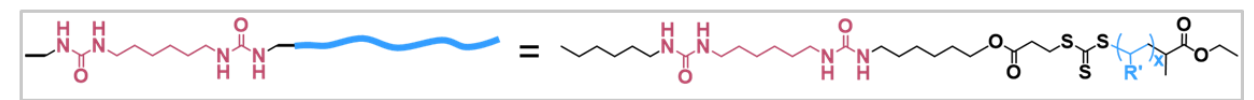

Scheme 1. (A) Structures of the bisurea-functionalized RAFT agent (TTC- $\mathbf{U}_{\mathbf{2}}$ ) and its urea-free counterpart (TTC-C 18 ). (B) Reaction scheme for the synthesis of the polymers studied in this work. Structures of the monomers used in this work: $N, N$-dimethylacrylamide (DMAc), acrylamide (AM), acrylic acid (AA), $N$-4-acryloylmorpholine (NAM) and 2-hydroxyethylacrylate (HEA). (C) Schematic representation of the expected supramolecular assembly of the bisurea-functionalized polymers via directional hydrogen bonding. 


\section{Synthesis of bisurea-functionalized hydrophilic polymers}

A series of bisurea-functionalized hydrophilic polymers (Scheme 1), namely $\operatorname{poly}(N, N$ dimethylacrylamide) (PDMAc), poly(acrylic acid) (PAA), polyacrylamide (PAM), poly(N-4acryloylmorpholine) (PNAM) and poly(2-hydroxyethylacrylate) (PHEA), were synthesized using the recently reported bisurea-functionalized RAFT agent TTC-U2. ${ }^{12,15}$ The polymerizations were performed in DMF, at $70{ }^{\circ} \mathrm{C}$, using $\mathrm{AIBN}$ as an initiator and targeting a number-average degree of polymerization $\left(D P_{\mathrm{n}}\right)$ ranging from 10 to 50 . Generally, $70 \%$ monomer conversion was reached in less than $5 \mathrm{~h}$ (see Table S1), and after precipitation the polymers were analyzed by SEC and ${ }^{1} \mathrm{H}$ NMR.

Table 1. Macromolecular characteristics and estimated cloud point $\left(\mathrm{CP}_{\mathrm{NE}}\right)$ in water of various bisureafunctionalized polymers.

Polymerizations are named X\#, where X refers to the nature of the polymer and the symbol \# corresponds to the $D P_{n, \text { conv }}$ of the polymer divided by 10.

\begin{tabular}{|c|c|c|c|c|c|c|}
\hline Expt. $^{a)}$ & $D P_{\mathrm{n}, \mathrm{conv}}{ }^{b)}$ & $D P_{\mathrm{n}, \mathrm{NMR}}{ }^{c}$ & $\begin{array}{c}M_{\mathrm{n}, \mathrm{NMR}}{ }^{c)} \\
\left(\mathrm{kg} \mathrm{mol}^{-1}\right)\end{array}$ & $\begin{array}{c}\text { Solubility in water at } \\
\text { RT }(5 w \%)\end{array}$ & $\begin{array}{l}C P_{\left.N E^{d}\right)} \\
(5 w t \%)\end{array}$ & $\begin{array}{c}\text { Morpho } \\
\text { cryo-TEM }^{e)}\end{array}$ \\
\hline PDMAc1 & 11 & 11 & 1.7 & $\checkmark$ & $30{ }^{\circ} \mathrm{C}$ & $\mathrm{C}$ \\
\hline PDMAc2 & 20 & 22 & 2.8 & $\checkmark$ & $45^{\circ} \mathrm{C}$ & $\mathrm{C}$ \\
\hline PDMAc3 & 29 & 34 & 4.0 & $\checkmark$ & $70{ }^{\circ} \mathrm{C}$ & $\mathrm{S}(\mathrm{C})$ \\
\hline PDMAc4 & 40 & 43 & 4.9 & $\checkmark$ & $>80^{\circ} \mathrm{C}$ & $\mathrm{S}(\mathrm{C})$ \\
\hline PAA2 & 15 & 20 & 2.1 & pH-dependent & pH-dependent & pH-dependent \\
\hline PAM2 & 22 & 24 & 2.4 & $\checkmark$ & $>70{ }^{\circ} \mathrm{C}$ & S \\
\hline PNAM1.7 & 17 & 18 & 3.2 & $x$ & $\leq 5^{\circ} \mathrm{C}$ & $\mathrm{C}(\mathrm{S})^{f}$ \\
\hline PNAM2.1 & 21 & 23 & 3.9 & $\checkmark$ & $32{ }^{\circ} \mathrm{C}$ & $\mathrm{S}(\mathrm{C})$ \\
\hline PHEA2 & 24 & 34 & 4.6 & $x$ & insoluble & n.d. \\
\hline PHEA4 & 41 & 47 & 6.1 & $x$ & $\begin{array}{l}\quad \leq 5^{\circ} \mathrm{C} \\
\text { (partially soluble) }\end{array}$ & $\left.\mathrm{C}(\mathrm{S})^{f}\right)$ \\
\hline
\end{tabular}

${ }^{\text {a) }}$ For details refer to Table S1; ${ }^{\text {b) }}$ The theoretical degree of polymerization, $D P_{\mathrm{n}, \text { conv }}$, was determined by ${ }^{1} \mathrm{H} \mathrm{NMR}$ using the monomer conversion (see Table S1); ${ }^{\text {c) }} D P_{\mathrm{n}}$ and $M_{\mathrm{n}}$ determined after purification by ${ }^{1} \mathrm{H}$ NMR through the relative integration of the polymerized monomer units and the bisurea end-group; ${ }^{\text {d) }}$ Cloud point determined with the naked eye, at $5 \mathrm{wt} \%$; ${ }^{\text {e) }}$ Morphology observed by cryo-TEM after spontaneous dissolution in water at $1 \mathrm{wt} \% . \mathrm{S}=$ spherical micelles, $\mathrm{C}=$ cylindrical micelles, the minority morphology is indicated in brackets, n.d. $=$ not determined; ${ }^{\mathrm{f}}$ Analysis performed on a solution prepared at a temperature below $5{ }^{\circ} \mathrm{C}$. 
The samples were named X\# (see Table 1), where X refers to the nature of the polymer and the symbol \# corresponds to the $D P_{\mathrm{n} \text {, conv }}$ of the polymer divided by 10 . As summarized in Table S1, the number-average molar masses, $M_{\mathrm{n}}$, determined by ${ }^{1} \mathrm{H}$ NMR $\left(M_{\mathrm{n}, \mathrm{NMR}}\right)$, through the relative integration of the polymerized monomer units and the bisurea end-group, were in good agreement with the theoretical $M_{\mathrm{n}}\left(M_{\mathrm{n}, \mathrm{th}}\right)$ showing a high chain-end functionalization. Moreover, in all cases, SEC analyses (Figure S1 and Table 1) showed that well-defined polymers with low dispersity were obtained $(\fallingdotseq<1.4)$. Generally, the polymerizations exhibited pseudo-first order kinetics and the molar masses increased linearly with monomer conversion (see for example the data for PDMAc4, Figure 1A and B), which is an additional sign for the control over the polymerization. Moreover, the SEC chromatograms remained narrow and symmetrical in shape in the course of the polymerization (Figure 1C).
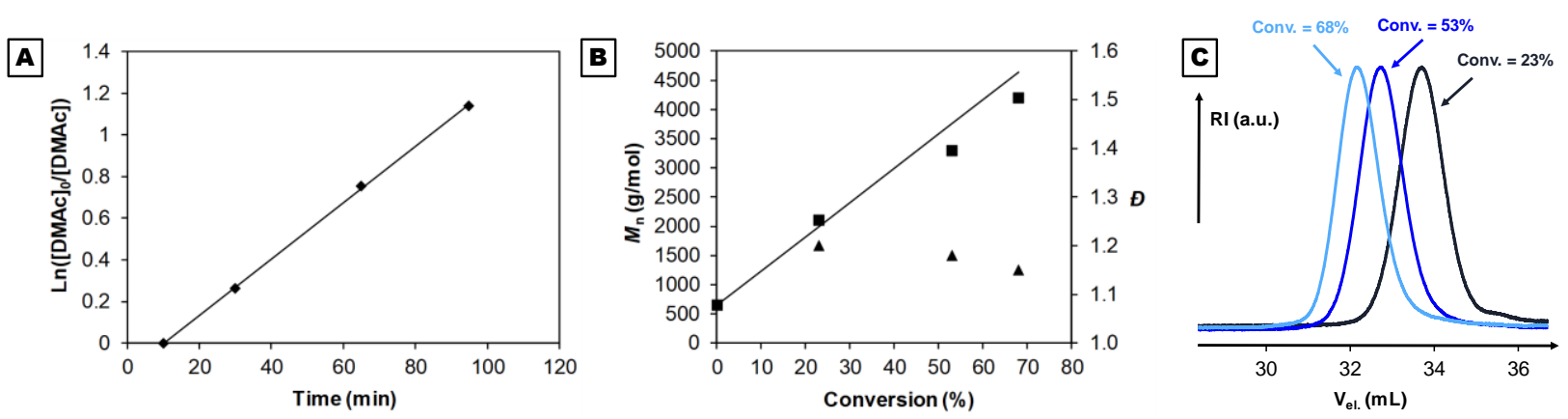

Figure 1. (A) Semilogarithmic kinetic curve for RAFT polymerization of DMAc at $70{ }^{\circ} \mathrm{C}$ in presence of $\mathbf{T T C}-\mathbf{U}_{2}$ performed with an initial molar ratio $[\mathrm{DMAc}] /\left[\mathbf{T T C}-\mathbf{U}_{2}\right] /[\mathrm{AIBN}]=59 / 1 / 0.05$. (B) Evolution of the $M_{\mathrm{n}}$ (square) (derived from a PMMA calibration) and $Ð$ (triangle) with monomer conversion. The black straight line represents the expected evolution of the $M_{\mathrm{n}, \mathrm{th}}$. (C) Evolution of the SEC chromatograms with monomer conversion (PDMAc4, Table 1).

\section{Self-assembly of the bisurea-functionalized polymers in water}

Most bisurea-functionalized polymers dissolved spontaneously in water ${ }^{\dagger}$ and were studied as is. Cryo-TEM analyses showed that they assembled into cylindrical and/or spherical micelles (Figure 2 and Figure S2), as described before for PDMAc- $\mathrm{U}_{2}$ and PAA- $\mathrm{U}_{2} .{ }^{12}$ Our data show that a lower $D P_{\mathrm{n}}$ favored the formation of cylindrical over spherical micelles (see Table 1). For

\footnotetext{
${ }^{\dagger}$ Except PHEA2, which was not soluble. PNAM1.7 and PHEA4 were soluble only below $5^{\circ} \mathrm{C}$.
} 
instance, by increasing gradually the $D P_{\mathrm{n}}$ of PDMAc- $\mathrm{U}_{2}$ from 11 to 43 , the length of the initially very long cylinders shortens and for $D P_{\mathrm{n}}=43$ mainly spheres and only few cylindrical micelles were formed. ${ }^{12}$ The critical $D P_{\mathrm{n}}$ for which cylindrical micelles were obtained clearly depended on the type of polymer (see Table 1). For instance, a majority of cylindrical micelles was observed for PHEA4 with a high $D P_{\mathrm{n}}=47$ (Figure 2A), but essentially spherical micelles were observed for PNAM2.1 with a lower $D P_{\mathrm{n}}=23$ (Figure S2). A further reduction of the $D P_{\mathrm{n}}$ below 20 was necessary to obtain cylindrical micelles (PNAM1.7, Figure 2B). In the same conditions, the bisurea-functionalized PAM of similar $D P_{\mathrm{n}} \sim 20$, PAM2, formed only spherical micelles. For PAA- $\mathrm{U}_{2}$, the morphology was $\mathrm{pH}$-dependent, as described before: aggregated fibers were formed at $\mathrm{pH} \leq 2.7$ and mainly spherical micelles were observed at $\mathrm{pH} \geq 7.8{ }^{12}$
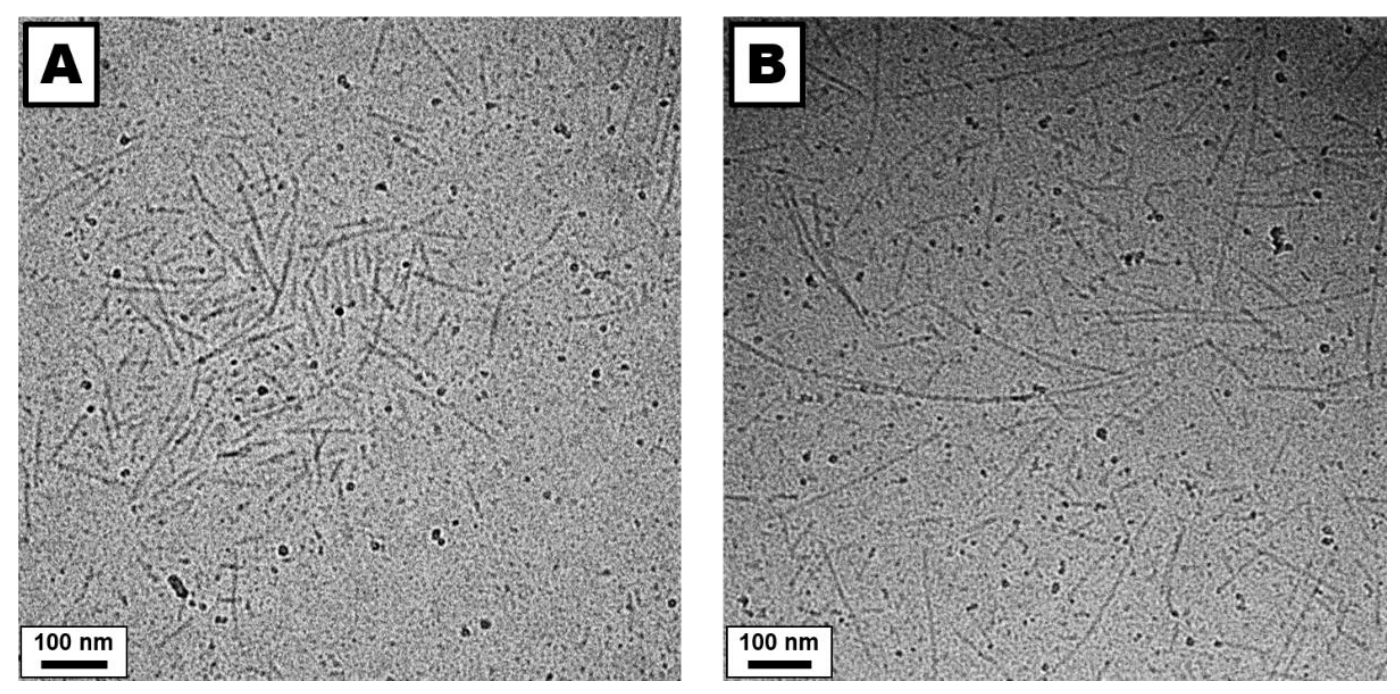

Figure 2. Representative cryo-TEM images of aqueous solutions of (A) PHEA4 and (B) PNAM1.7 prepared at $1 \mathrm{wt} \%$ by direct dissolution in water. The dark spots are contaminations stemming from water crystals on the sample surface.

\section{Temperature-dependent solubility and cloud point of the bisurea-functionalized polymers}

We observed that some of the bisurea-functionalized PNAM and PHEA exhibited a low water solubility: PNAM1.7, PHEA2 and PHEA4 were insoluble in water at room temperature; samples PNAM1.7 and PHEA4 became soluble by decreasing the temperature below $5{ }^{\circ} \mathrm{C}$. The solubility was thus dependent on $D P_{\mathrm{n}}$ and increased with increasing length of PHEA and 
PNAM, respectively (Table 1). It should be noted that the bisurea-free polymers are highly soluble in water and do not exhibit any thermoresponsive behavior (at least not below 100 $\left.{ }^{\circ} \mathrm{C}\right) .{ }^{16,17}$ Concerning the PDMAc- $\mathrm{U}_{2}$ samples, they were all soluble at room temperature, but a cloud point was observed when the solutions were heated. Just as for PNAM and PHEA, the critical solubility was also $D P_{\mathrm{n}}$-dependent: As reported in Table $\mathbf{1}$ and illustrated in Figure $\mathbf{S 3}$, the cloud point observed by the naked eye $\left(\mathrm{CP}_{\mathrm{NE}}\right)$ increased from $30{ }^{\circ} \mathrm{C}\left(\mathbf{P D M A c 1}, D P_{\mathrm{n}}=11\right)$ to $45^{\circ} \mathrm{C}\left(\right.$ PDMAc2, $\left.D P_{\mathrm{n}}=22\right)$ to $70{ }^{\circ} \mathrm{C}\left(\right.$ PDMAc3, $\left.D P_{\mathrm{n}}=34\right)$. For an even longer PDMAc segment (PDMAc4, $\left.D P_{\mathrm{n}}=43\right)$, no cloud point was observed, the polymer was soluble over the whole temperature range investigated $\left(5^{\circ} \mathrm{C}\right.$ to $\left.80^{\circ} \mathrm{C}\right)$. These values are far below the calculated cloud point reported for PDMAc $\left(216{ }^{\circ} \mathrm{C}\right)$ by Tahoces et al. ${ }^{18}$ To exclude that simple hydrophobic effects were responsible for the great decrease in cloud point, Figure S3 shows the comparison of the aqueous solutions of PDMAc- $\mathrm{U}_{2}$ and the corresponding octadecylfunctionalized polymer PDMAc ${ }_{19}-\mathrm{C}_{18}$ (M-PDMAc2, Table S1). No cloud point was observed for the latter solution (at least up to $80^{\circ} \mathrm{C}$ ) (Figure S3 C and D), demonstrating the crucial role of the bisurea sticker in the thermo-responsiveness of the functionalized PDMAc- $\mathrm{U}_{2}$ polymers.

The presence of a cloud point, which evolves with the $D P_{\mathrm{n}}$ of the polymer, was thus a general feature of bisurea-functionalized hydrosoluble polymers.

Comparing the different bisurea-functionalized polymers with similar $D P_{\mathrm{n}}$, significant differences in the cloud point values are observed (Table 1). The solubility of the polymers decreases in the order PAM2 > PDMAc2 > PNAM1.7 > PHEA2. By comparison with the octanol-water partition coefficients of the studied monomers $\left(\log \mathrm{P}^{\mathrm{AM}}=-0.7<\log \mathrm{P}^{\mathrm{DMAc}}=-0.3\right.$ $\left.<\log \mathrm{P}^{\mathrm{HEA}}=-0.2<\log \mathrm{P}^{\mathrm{NAM}}=-0.1\right),{ }^{19,20,21}$ we can assume that the less hydrophilic the monomer unit (typically NAM or HEA) is, the less soluble is the polymer and the lower is the cloud point. Concerning the weak polyelectrolyte $\mathrm{PAA}_{20}-\mathrm{U}_{2}$ (PAA2), we observed that the cloud point depended strongly on the $\mathrm{pH}$. Indeed, at the natural $\mathrm{pH}$ of 3.9, the polymer solution (at $5 \mathrm{wt} \%$ ) was transparent and no cloud point was detected up to $80^{\circ} \mathrm{C}$. By diminishing the $\mathrm{pH}$ to 2 , at which PAA- $\mathrm{U}_{2}$ is quasi fully protonated ${ }^{22}$ and forms aggregated fibers, ${ }^{12}$ the solution of $\mathrm{PAA}_{20^{-}}$ $\mathrm{U}_{2}$ became turbid at room temperature. In view of the previous observations, we can reasonably assume that the bisurea-driven assembly into cylindrical micelles is responsible for the decrease in polymer solubility and the observation of a cloud point. 
In terms of macromolecular architecture, one might compare our supramacromolecular 1D assemblies to high molar mass (supra)macromolecular bottle-brush type polymers. ${ }^{14,23}$ In principle, the lower critical solution temperature (LCST) of polymers is reduced with increasing $M_{\mathrm{n}}$ due to the loss of entropy of mixing $\Delta \mathrm{S}_{\mathrm{m}} \cdot{ }^{1,24,25}$ Considering our assemblies as bottle-brushes, the same tendency was observed: decreasing the $M_{\mathrm{n}}$ of the PDMAc- $\mathrm{U}_{2}$ chains increases the length of the cylindrical micelles, so to say the $M_{\mathrm{n}}$ of the bottle-brushes, leading to a decrease of the cloud point. However, in the literature this decrease in transition temperature with $M_{\mathrm{n}}$ is usually only of a few degrees - in contrast to the drastic decrease observed here. ${ }^{\ddagger 26}$ We should therefore consider additional effects that might contribute to the observed important loss of solubility at higher temperature. One possibility is the hydrophobic effect, which greatly diminishes the entropic contribution of the Gibbs free energy of mixing. ${ }^{1,27,28}$ As such, one might envisage that, at low temperatures, the bisurea chain-ends assemble in water in a way that exposes part of the methylene units to the water, thus creating hydrophobic domains that are forced to be in contact with water because of the constraints imposed by the hydrogen bonded ureas (unlike the simple alkyl chain of PDMAc- $\mathrm{C}_{18}$ which can form micelles where the hydrophobic chains are fully shielded from water). Increasing the temperature would lead to aggregation of the individual objects via the hydrophobic domains. Consequently, a loss of water-solubility and a cloud point at rather low temperatures is observed.

\section{Investigation of the temperature-dependent behavior of bisurea-functionalized PDMAc}

To better understand the observed cloud point, additional characterizations were performed on bisurea-functionalized PDMAc polymers. So far simply observed with the naked eye on fairly concentrated solutions ( $5 \mathrm{wt} \%$ ), we decided to determine more precisely the cloud point by DLS on $0.1 \mathrm{wt} \%$ diluted bisurea-functionalized PDMAc solutions. For each polymer solution, an increase of the derived count rate with temperature was observed indicating the formation of large light scattering aggregates (Figure 3).

\footnotetext{
$\$$ Grafting of macromolecular chains on surfaces is also known to lower the CP, but the effect is also much weaker than presented here. ${ }^{26}$
} 


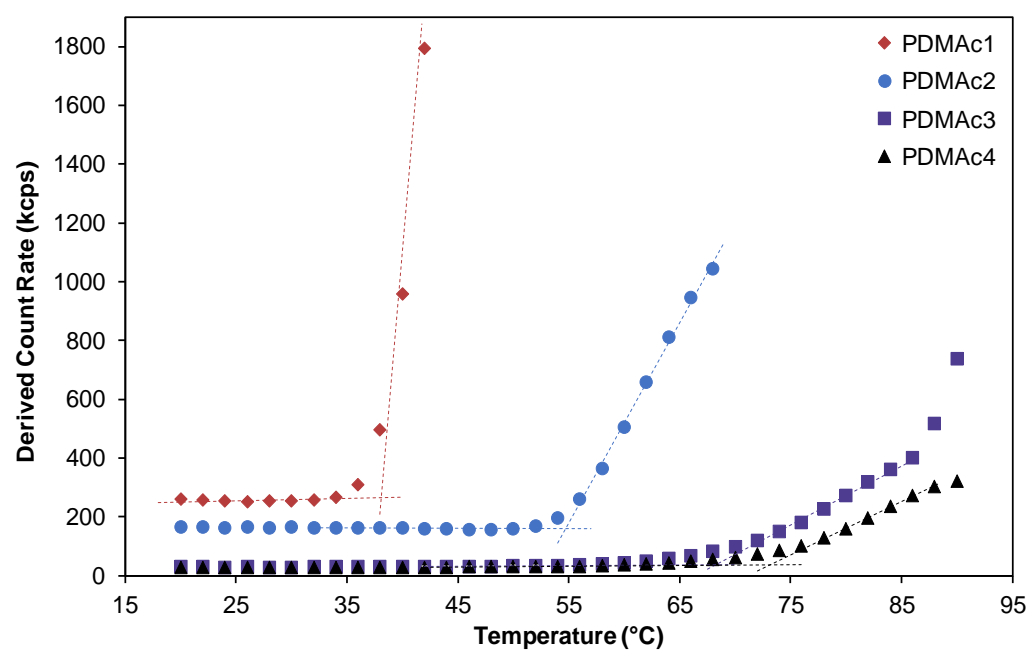

Figure 3. DLS analysis: evolution of the derived count rate (kcps) with the temperature for bisureafunctionalized PDMAc of different $M_{\mathrm{n}}(0.1 \mathrm{wt} \%)$.

This latter effect was confirmed by monitoring the z-average diameter $\left(D_{z}\right)$ of the particles with temperature (see for example the evolution of the $\mathrm{D}_{z}$ with temperature for PDMAc2 at $0.1 \mathrm{wt} \%$ in Figure S4A). For comparison, bisurea-free PDMAc- $\mathrm{C}_{18}$ solutions were also analyzed by DLS: no significant increase of the derived count rate was observed by heating the solutions from $20{ }^{\circ} \mathrm{C}$ to $75^{\circ} \mathrm{C}$, confirming the role of the bisurea sticker in the observed cloud point (see for example the results for M-PDMAc1 in Figure S4B).

The DLS analyses confirmed that the CP increased with increasing the $D P_{\mathrm{n}}$. For the highest molar mass polymer PDMAc4 only a very slight increase of the derived count rate above 73 ${ }^{\circ} \mathrm{C}$ was observed. The cloud points determined by this method (Figure 3), labelled CPDLS and listed in Table 2 are consistent with the values determined with the naked eye (at $5 \mathrm{wt} \%$ in water), termed $\mathrm{CP}_{\mathrm{NE}}$ (Table 1). The weak concentration dependence of the cloud point was confirmed by DLS and turbidimetry analyses (see SI, Figures S5 and S6).

To better understand the temperature-sensitivity of the samples, nano-DSC analyses were performed on aqueous solutions of PDMAc- $\mathrm{U}_{2}$ at constant molar concentrations $(12 \mathrm{mM}$, corresponding to mass concentrations between 2.5 and $7 \mathrm{wt} \%$ ). The results are displayed in Figure 4. For PDMAc1, in the temperature range in which the cloud point was formerly observed $\left(30-40{ }^{\circ} \mathrm{C}\right)$, no transition was recorded, but an endothermic transition at $83{ }^{\circ} \mathrm{C}$ was observed. By increasing the molar mass of the polymer (PDMAc2) the endothermic transition was significantly shifted towards lower temperature $\left(68^{\circ} \mathrm{C}\right)$, which remained above the cloud 
point. For higher $D P_{\mathrm{n}}$ PDMAc-U $_{2}$ (PDMAc3bis ${ }^{\S}$ and PDMAc4) a further decrease of the transition temperature ( $\left.\mathrm{TT}_{\text {nanoDSC}}\right)$ was observed. The molar mass dependency of this endothermic transition is thus the opposite of the cloud point dependency, as summarized in Figure 5 (compare the evolution of $\mathrm{CP}_{\mathrm{DLS}}$ (or $\mathrm{CP}_{\mathrm{NE}}$ ) and $\mathrm{TT}_{\text {nanoDSC }}$ with molar mass). The enthalpy of the endothermic transition was determined to be about $45 \mathrm{~kJ} \mathrm{~mol}^{-1}$ for PDMAc1 and about $20 \mathrm{~kJ} \mathrm{~mol}^{-1}$ for the longer PDMAc-U 2 polymers (PDMAc2, PDMAc3bis and PDMAc4), which is actually in the range of the bisurea H-bonding energy. ${ }^{29}$ The observed difference between polymers of different molar mass (i.e. $\Delta \mathrm{H}($ PDMAc1) $>\Delta \mathrm{H}$ (other PDMAc$\left.\mathrm{U}_{2}\right)$ ) might be related to the type of the assemblies formed in water.

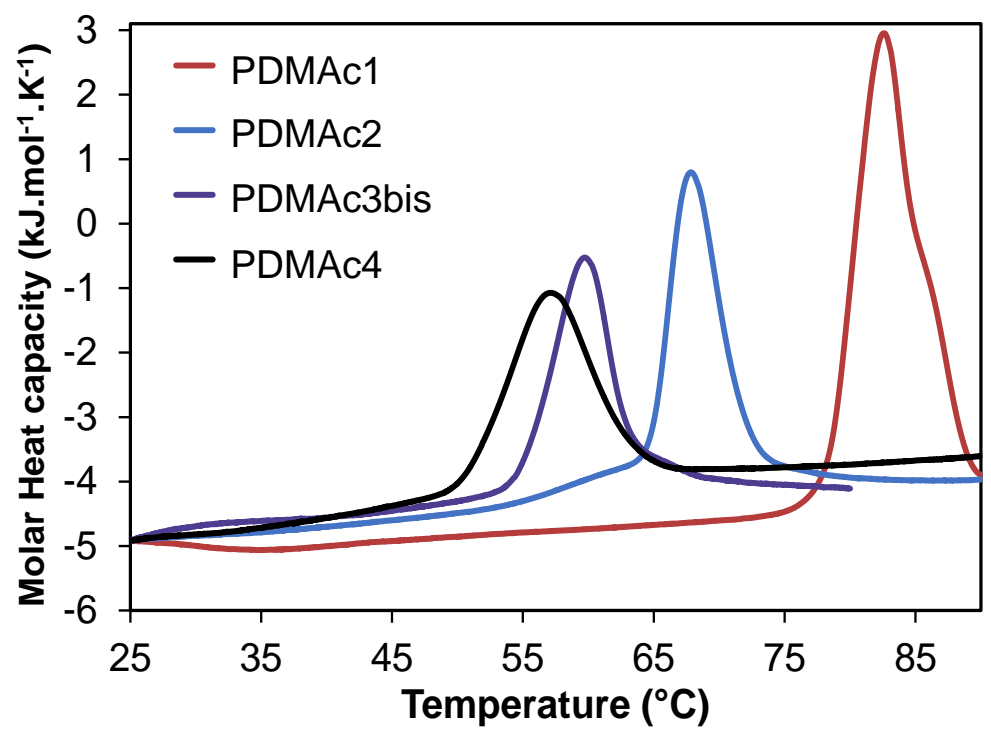

Figure 4. Nano-DSC analyses of the bisurea-functionalized PDMAc solutions at $\sim 12 \mathrm{mM}$ (second heating run).

$\S$ PDMAc3bis is the reproduction of experiment PDMAc3 (see Table S1). 


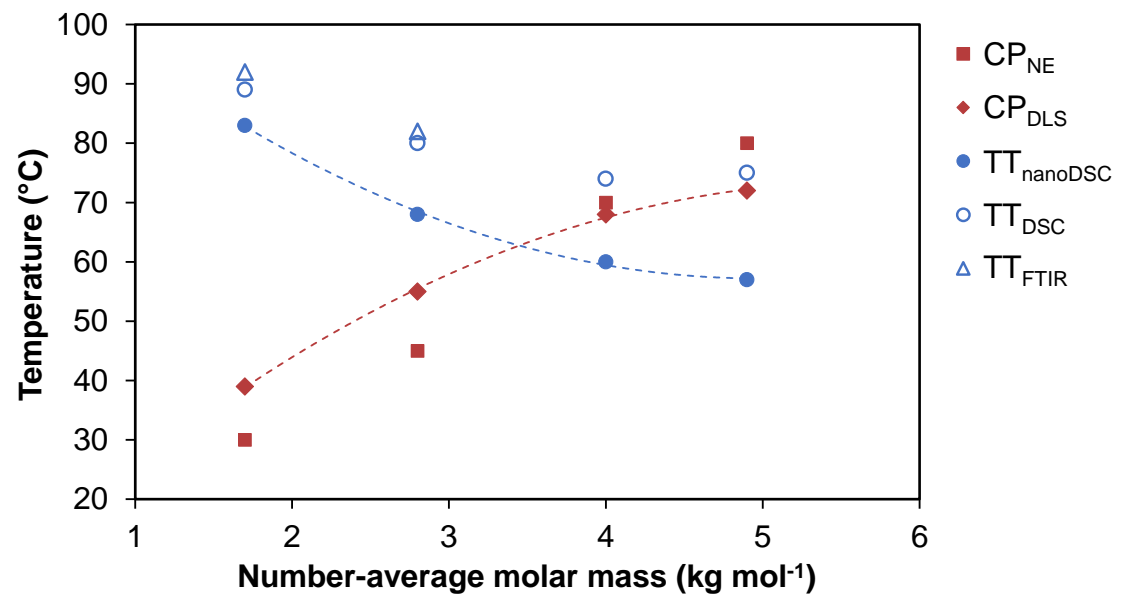

Figure 5. Evolution of the cloud point $\left(\mathrm{CP}_{\mathrm{NE}}\right.$ and $\left.\mathrm{CP}_{\mathrm{DLS}}\right)$ and the endothermic transition temperature $\left(\mathrm{TT}_{\text {nanoDSC}}\right)$ with the molar mass of the PDMAc- $\mathrm{U}_{2}$ polymers, determined by analyses on aqueous solutions (full symbols). The solid state transition temperatures measured on films (TT $\mathrm{TTIR}_{\mathrm{F}}$ ) or powders $\left(\mathrm{TT}_{\mathrm{DSC}}\right)$ are indicated as empty symbols.

In addition to the nano-DSC analyses on the aqueous solutions, lyophilisates of the solutions were analyzed by DSC (Figure S7). Freeze-drying should indeed preserve the supramolecular organization of the polymer chains in solution within the dried powders. Whatever the molar mass of the polymer, an endothermic transition was observed on the thermograms, similar to the nano-DSC results obtained on polymer solutions. The transition temperature $\left(\mathrm{TT}_{\mathrm{DSC}}\right)$ values are reported in Table 2 and Figure S7.

The TT $_{\text {DSC }}$ determined by DSC was in the same range and followed the same trend as the

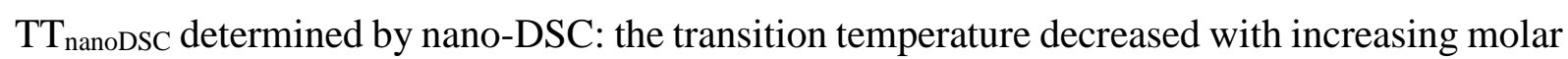
mass of the polymer. ${ }^{*}, \dagger i$ In view of these results, we can reasonably consider that the endothermic transitions observed in the solid state and in aqueous solution originate from the same phenomenon. At this stage, we may only assume that the transitions involve H-bonding

\footnotetext{
*** $\mathrm{TT}_{\mathrm{DSC}}$ was generally above $\mathrm{TT}_{\text {nanoDSC. }}$. We may assume that the transitions involve breaking of hydrogen bonds (see below), which may be influenced by the presence of water.

"Interestingly, while the transition in bulk was reversible for low molar mass polymers (PDMAc1 and PDMAc2), a glass transition instead of an endothermic transition was observed on the thermograms of higher $D P_{\mathrm{n}}$ samples PDMAc3 and PDMAc4 for the second heating run (Figure S7). This transition is therefore not reversible for high molar mass polymers due to the low content of urea functions in the sample, at least not in the conditions chosen for the DSC measurements, possibly for kinetic reasons.
} 
Plotting the intensity at $3330 \mathrm{~cm}^{-1}$ vs temperature (Figure 6C) revealed a progressive dissociation with a distinct transition around $90{ }^{\circ} \mathrm{C}$, which is actually close to the transition temperature observed by DSC on the freeze-dried samples. In addition, the evolution of the vibration band of free urea $\mathrm{C}=\mathrm{O}$ functions $\mathrm{s}^{31,32,33}\left(1680 \mathrm{~cm}^{-1}\right)$ confirmed the dissociation of the bisurea stickers: an increase of this band was observed with the increase of temperature (Figure 6B). The same observations were made for PDMAc2 (Figure S9) for which a slightly lower transition temperature was observed around $80{ }^{\circ} \mathrm{C}$, matching the endothermic transition of PDMAc2 observed on dried nanofibers by DSC (Table 2).

In conclusion, FTIR analyses evidenced the temperature-induced dissociation of H-bonded bisureas in PDMAc- $\mathrm{U}_{2}$ polymers and confirmed that the endothermic transition observed on aqueous solutions and on freeze-dried solutions (bulk) was due to the dissociation of H-bonded bisureas.
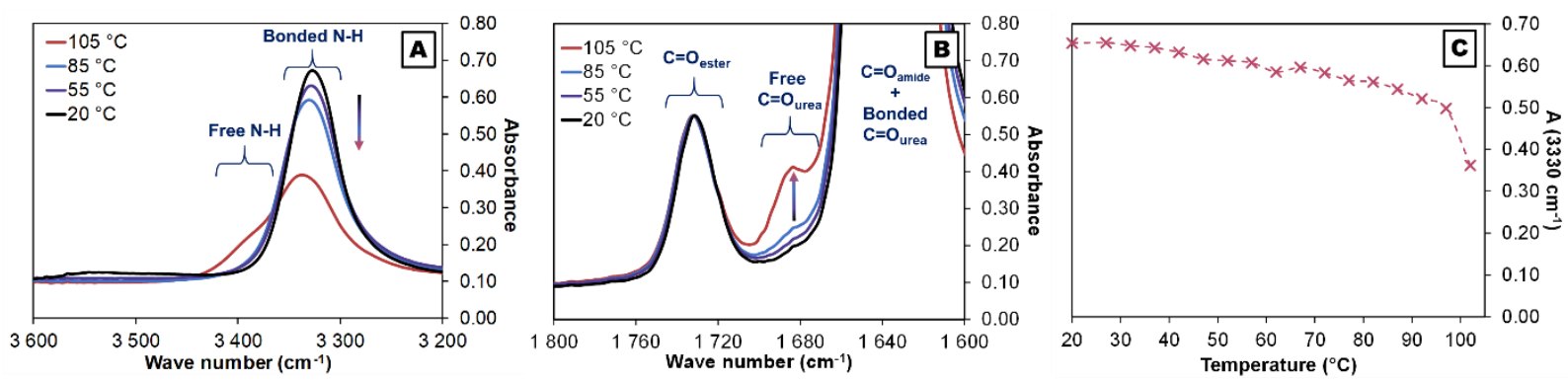

Figure 6. VT-FTIR analysis on solid film of PDMAc1: Normalized FTIR spectra in the N-H (A) and $\mathrm{C}=\mathrm{O}$ (B) vibration areas. (C) Absorbance at $3330 \mathrm{~cm}^{-1}$ versus temperature (heating run).

SANS experiments were performed on PDMAc2 with $\mathrm{CP}_{\mathrm{DLS}}\left(55^{\circ} \mathrm{C}\right)<\mathrm{TT}_{\text {nanoDSC }}\left(68^{\circ} \mathrm{C}\right)$, and PDMAc4 with $\mathrm{TT}_{\text {nanoDSC }}\left(57^{\circ} \mathrm{C}\right)<\mathrm{CP}_{\text {DLS }}\left(73^{\circ} \mathrm{C}\right)$, at different temperatures (Figure 7). At low temperature, both systems exhibit in the low q region a q ${ }^{-1}$ dependence of the scattered intensity that is characteristic for rigid cylinders. In agreement with our previous study, ${ }^{12}$ the scattering can be quantitatively accounted for by a mixture of short and long core-shell cylinders, with a radius of the core $(2.6 \mathrm{~nm})$ that is compatible with the dimension of the hydrophobic part of the polymers (see details in SI). In the case of PDMAc2 (Figure 7A), at $20{ }^{\circ} \mathrm{C}$ long and short cylinders are present in similar amounts and their structure is affected very little up to $50{ }^{\circ} \mathrm{C}$. Then at $60{ }^{\circ} \mathrm{C}$, a strong increase of the intensity at low q (below $0.005 \AA^{-1}$ ) suggests the formation of large aggregates, in agreement with the cloud point of $55{ }^{\circ} \mathrm{C}$ determined by light scattering. At $85^{\circ} \mathrm{C}$ (i.e. above both $\mathrm{CP}_{\mathrm{DLS}}$ and $\mathrm{TT}_{\text {nanoDSC }}$ ), the analysis of PDMAc2 showed a 
$\mathrm{q}^{-3}$ dependence of the scattered intensity in the low q region and a correlation peak at higher $\mathrm{q}$ $\left(0.07 \AA^{-1}\right)$. These features suggest the formation of aggregates of spheres with a homogeneous interparticle distance. A quantitative fit is possible with a model of fractal aggregates of primary spheres of radius $2.6 \mathrm{~nm}$ that are packed in close contact with a correlation length of $9 \mathrm{~nm}$ into larger clusters of radius $28 \mathrm{~nm}$ (see details in SI). The breaking of the cylinders into (aggregated) spheres is possibly the result of the breaking of the hydrogen bonds above $\mathrm{TT}_{\text {nanoDSC }}=68{ }^{\circ} \mathrm{C}$. In the case of PDMAc4 (Figure 7B), at $20^{\circ} \mathrm{C}$ short cylinders are the main objects present with a volume fraction of long cylinders of only $8 \%$. At 50 and $65{ }^{\circ} \mathrm{C}$, the scattered intensity at intermediate $\mathrm{q}$ values $\left(0.005<\mathrm{q}<0.05 \AA^{-1}\right)$ decreases with no sign of aggregation at low $\mathrm{q}$. Quantitative fit of the data is possible with a reduced amount of short core-shell cylinders at high temperature, indicating their disassembly, presumably into unimers (see SI). This disassembly is possibly the result of the breaking of the hydrogen bonds detected by FTIR in this temperature range $\left(\mathrm{TT}_{\text {nanoDSC }}=57^{\circ} \mathrm{C}\right)$. At $85^{\circ} \mathrm{C}$ (i.e. above $\mathrm{CP}$ DLS $)$, the increase of the low $\mathrm{q}$ intensity is a clear sign of aggregation. The lower slope at low q (compared to that of PDMAc2) and the absence of a correlation peak at higher $q$ indicate that the aggregates of PDMAc4 are less dense than those of PDMAc2. A quantitative fit is still possible with a model of fractal aggregates of primary spheres of radius $2.6 \mathrm{~nm}$ that are packed into clusters of radius $13 \mathrm{~nm}$ with a fractal dimension of 2.0 (see details in SI).
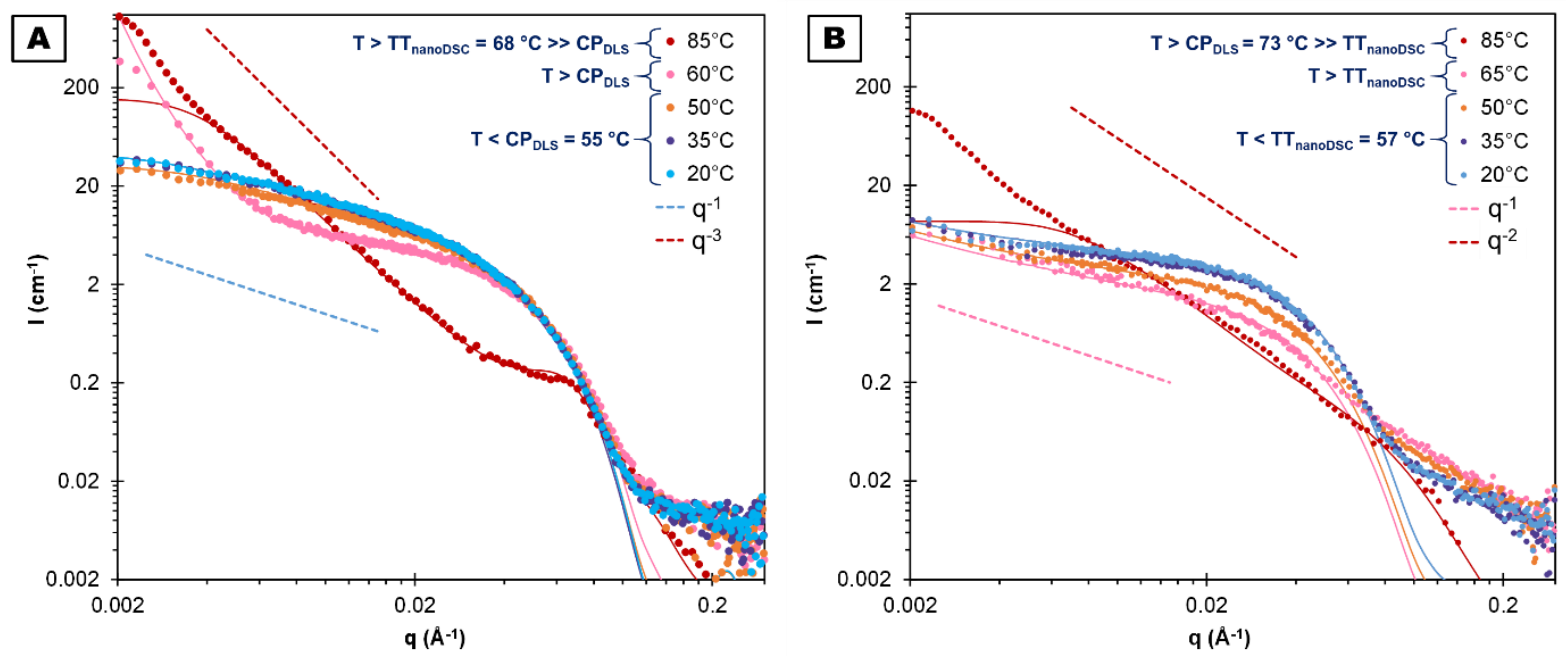

Figure 7. SANS intensity (I) versus scattering vector (q) for PDMAc2 (A) and PDMAc4 (B) solutions in $\mathrm{D}_{2} \mathrm{O}$ at $1 \mathrm{wt} \%$, at different temperatures. The discrepancy between the model and the experiment at high $\mathrm{q}$ is because the solvated polymer chains at the surface of the objects are not explicitly taken into account by the form factor of a simple cylinder. 
In summary, all the analyses performed on aqueous solutions of PDMAc- $\mathrm{U}_{2}$ revealed the presence of two distinct transitions. (1) A visually observable cloud point, which could be detected by both DLS and SANS analyses, indicates the aggregation of individual nano-objects. (2) An endothermic transition, revealed by (nano-)DSC and FTIR analyses, which is due to the dissociation of the H-bonded bisureas. $*$ The cloud point temperature increases with increasing molar mass of the polymers, whereas the endothermic transition has the inverse molar mass dependency. These transitions are thus driven by different mechanisms, and two cases have to be considered: a first case for the shorter PDMAc-U2 polymers (PDMAc1 and PDMAc2), for which the cloud point is below the endothermic transition, and the opposite case for the longer PDMAc-U $\mathrm{U}_{2}$ polymers (PDMAc3 and PDMAc4) (Figure 5).

\footnotetext{
\$I It should be noted that the endothermic transition was not only observed for PDMAc- $\mathrm{U}_{2}$, but is a general feature of bisurea-functional polymers and was also observed for bisurea-functionalized PAM2 and PAA2 at $83{ }^{\circ} \mathrm{C}$ and $57{ }^{\circ} \mathrm{C}$, respectively (Figure $\mathbf{S 1 3}$ ).
} 


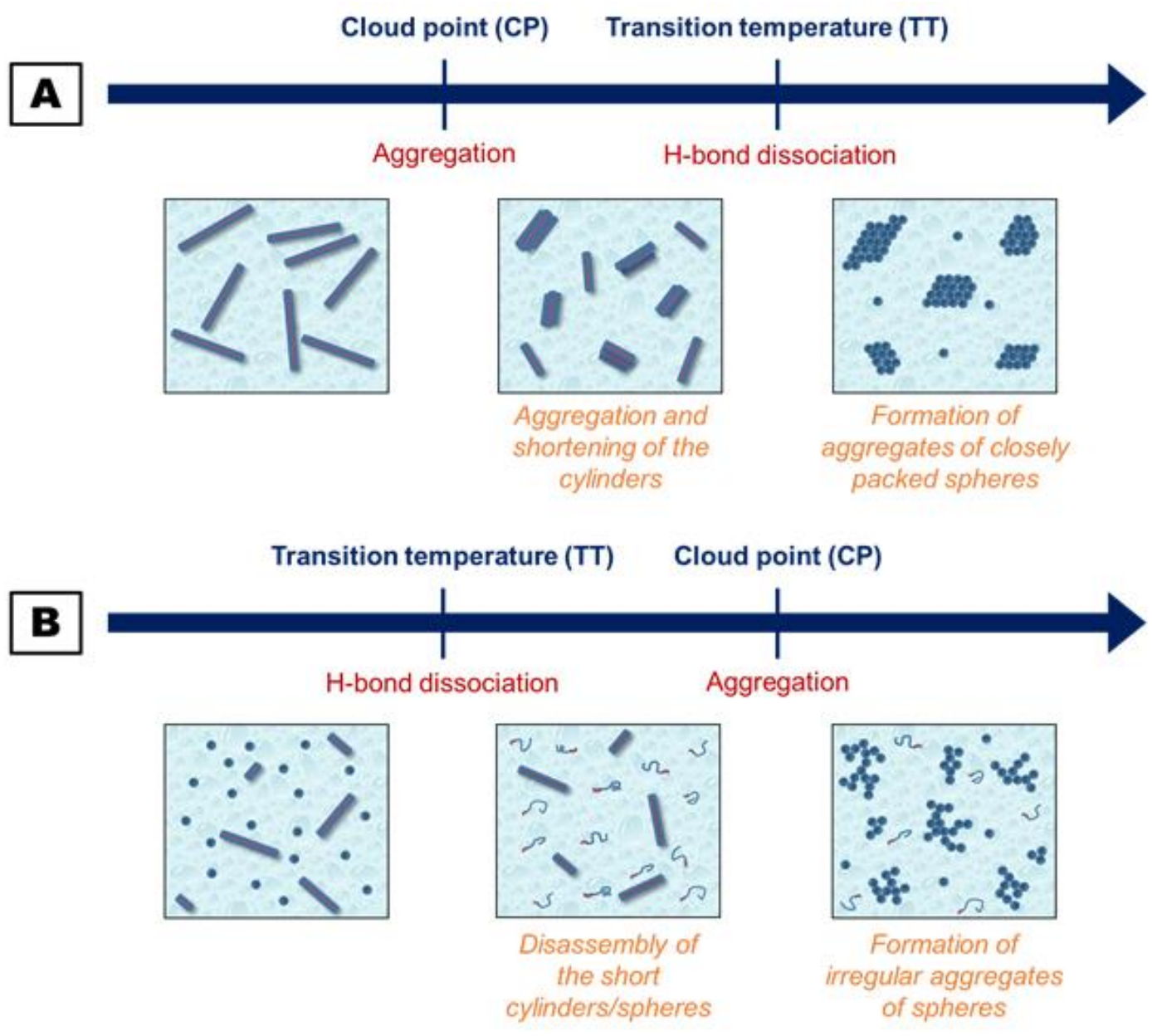

Scheme 2. Proposed schematic representation of the mechanisms involved in the temperature-dependent behavior of bisurea-functionalized PDMAc in the case of (A) CP $<$ TT and (B) CP $>$ TT.

Tuning the cloud point and the transition temperature using mixtures of bisureafunctionalized PDMAc

Knowing that the molar mass of the polymers significantly affects the thermo-responsiveness of the bisurea-functionalized nano-assemblies, we investigated the possibility to tune the transition temperatures by using mixtures of bisurea-functionalized PDMAc of different molar masses. We thus characterized mixtures of PDMAc1 $\left(M_{\mathrm{n}, \mathrm{NMR}}=1.7 \mathrm{~kg} \mathrm{~mol}^{-1}\right)$ and PDMAc4 $\left(M_{\mathrm{n}, \mathrm{NMR}}=4.9 \mathrm{~kg} \mathrm{~mol}^{-1}\right)$ in aqueous solution at different concentrations by nano-DSC, DLS and cryo-TEM. 
Firstly, solutions of PDMAc1/PDMAc4 blends were analyzed by nano-DSC (Figure S14). Whatever the content of PDMAc4 in the mixture, a single endothermic transition lying in between the ones of the pure polymer solutions were observed, indicating the formation of mixed aggregates. Moreover, the transition temperature decreased with the increasing fraction of PDMAc4 in the blend (Figure 8).

In addition, we analyzed diluted aqueous solutions of PDMAc1/PDMAc4 blend by DLS to determine their $\mathrm{CP}_{\mathrm{DLS}}$ (Figure S15). The strong evolution of the $\mathrm{CP}_{\mathrm{DLS}}$ with PDMAc4 content in the blend is displayed in Figure 8. For example, adding only 8 mol\% of PDMAc4 to PDMAc1 increased the cloud point by $13{ }^{\circ} \mathrm{C}$. Interestingly, we also observed that the evolution of the cloud point was not linear with the PDMAc4 content, and could even exceed the one of both pure polymer solutions. These results confirm that PDMAc1 and PDMAc4 do not form individual assemblies in aqueous solution but mixed aggregates with an increased overall solubility.
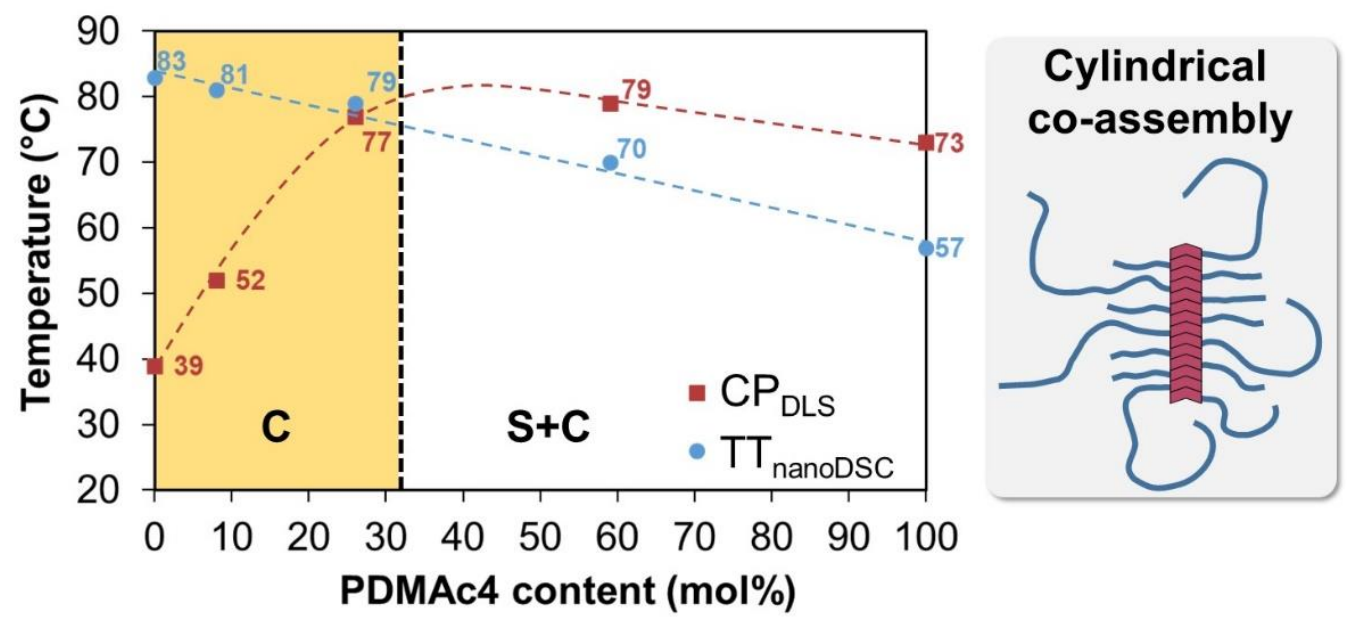

Figure 8. Evolution of the cloud point $\left(\mathrm{CP}_{\mathrm{DLS}}\right)$, the transition temperature $\left(\mathrm{TT}_{\text {nanoDSC }}\right)$ and the morphology of PDMAc1/ PDMAc4 mixtures with composition. $\mathrm{C}=$ cylindrical micelles; $\mathrm{S}+\mathrm{C}$ $=$ mixture of spheres and cylindrical micelles. The dashed lines are guides to the eyes. The sketch on the right side is a schematic representation of a cylindrical co-assembly. 

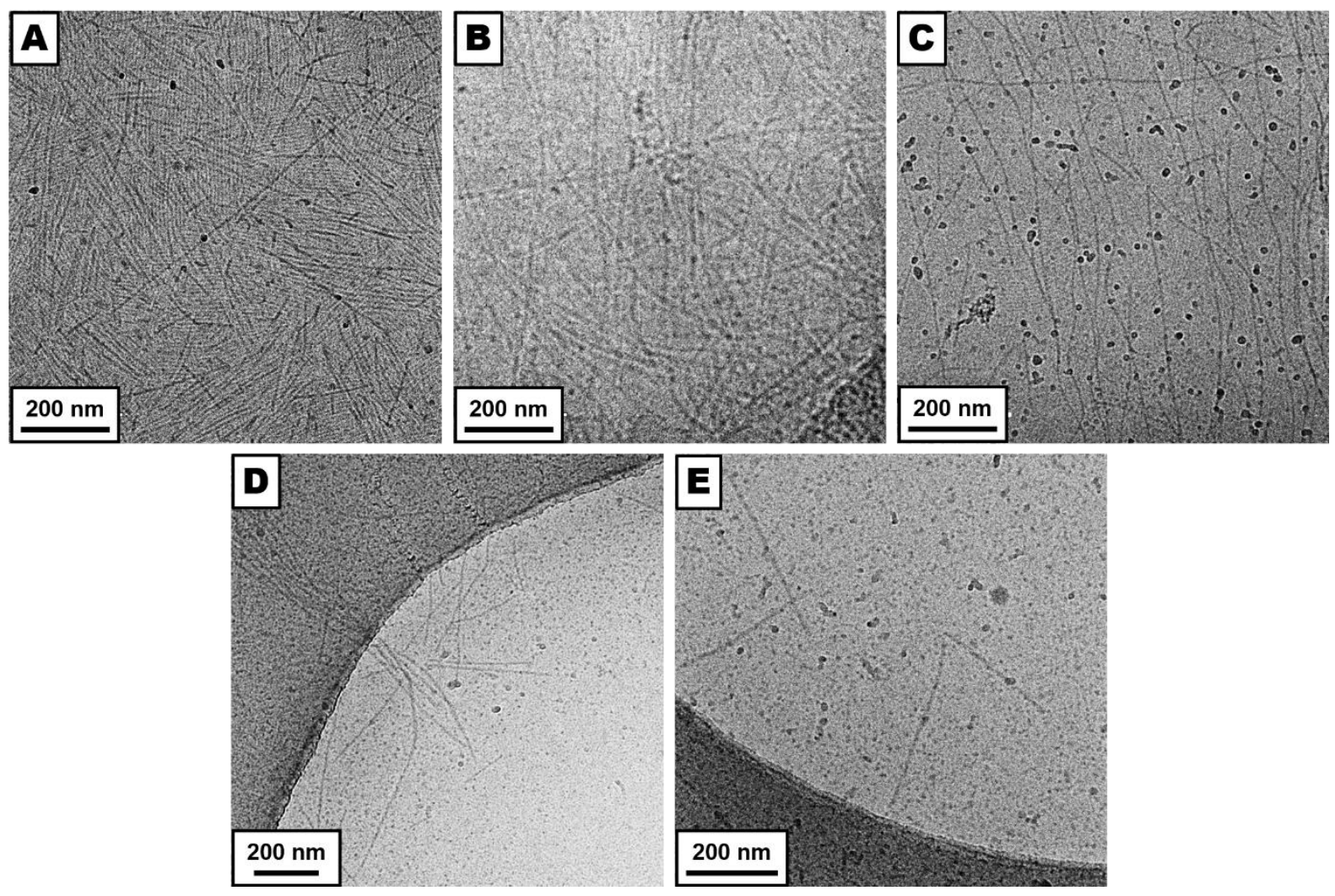

or
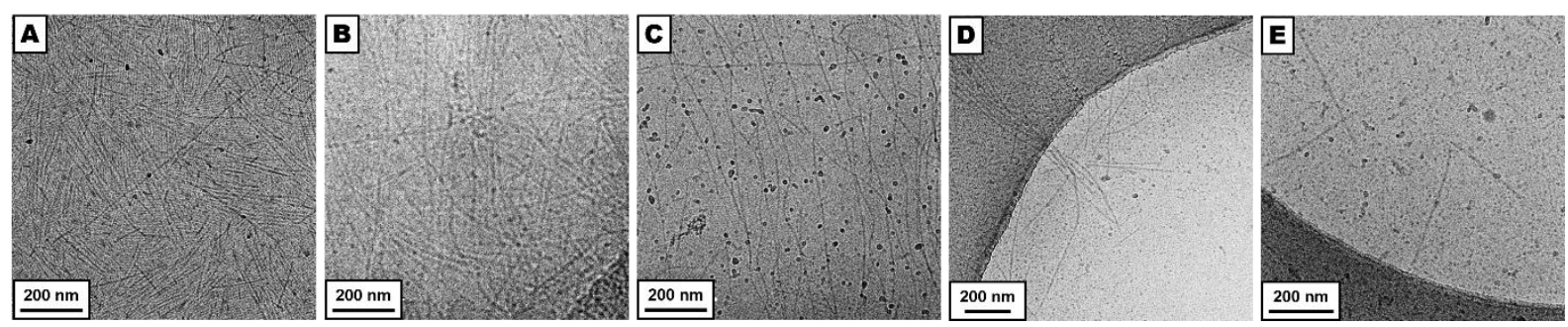

Figure 9. Representative cryo-TEM images of aqueous solutions (prepared at $1 \mathrm{wt} \%$ ) of PDMAc1/ PDMAc4 mixtures with different PDMAc4 content ( $\mathrm{x}$ mol\%): (A) $\mathrm{x}=0 ;(\mathrm{B}) \mathrm{x}=8$; (C) $x=26$; (D) $x=59$ (E) $x=100$. The dark spots are contaminations stemming from water crystals on the sample surface.

Each blend was also characterized by cryo-TEM (Figure 9). PDMAc-U $\mathrm{U}_{2}$ with the lowest molar mass PDMAc1 $\left(M_{\mathrm{n}, \mathrm{NMR}}=1.7 \mathrm{~kg} \mathrm{~mol}^{-1}\right)$ formed long cylindrical micelles after direct dissolution in water at $1 \mathrm{wt} \%$ (Figure 9A), whereas spherical micelles were predominant and long cylinders were rarely observed in the case of the longer PDMAc4 (Figure 9E). ${ }^{12}$ In contrast, for the mixtures, long cylindrical micelles were mainly observed, at least up to 26 mol\% of PDMAc4 (Figure 9B and C). One can thus conclude that the transition temperature of PDMAc- $\mathrm{U}_{2}$ 
polymer nano-assemblies can be tuned between 39 and $77^{\circ} \mathrm{C}$, while maintaining cylinders as the main morphology (mixture with 0 to $26 \mathrm{~mol} \%$ of PDMAc4). The presence of some PDMAc- $U_{2}$ with a long polymer block (PDMAc4) in the cylindrical structure, is expected to create defects (see scheme in Figure 8) that may be responsible for the remarkable solubility increase for the co-assemblies, assuming that the defects disfavor inter-assemblies interactions. Although the origin for this synergistic solubility increase is not clarified yet, we investigated it in other PDMAc-U $\mathrm{U}_{2}$ mixtures. Figure S16A shows that the synergy is present when PDMAc1 is mixed with either PDMAc3 or PDMAc4. In these mixtures the contrast in size between the short and long components is quite large: it can be quantified in dimensionless units as

$\Delta \mathrm{Rg}=\left(\mathrm{DP}_{\text {long }}\right)^{0.5}-\left(\mathrm{DP}_{\text {short }}\right)^{0.5}$

if a gaussian conformation is assumed, where $\mathrm{DP}_{\text {long }}$ (resp. $\mathrm{DP}_{\text {short}}$ ) is the degree of polymerization of the long (resp. short) component. We find $\Delta \mathrm{Rg}=2.5$ or 3.2 for these mixtures (PDMAc1/PDMAc3 or PDMAc1/PDMAc4, respectively). In contrast, a monotonous evolution occurs when PDMAc2 is mixed with either PDMAc3 or PDMAc4 (Figure S16B). In these mixtures the contrast in size between the short and long components ( $\Delta \mathrm{Rg}=1.1$ or 1.9$)$ is smaller. Therefore, the contrast in size between the two components seems essential to generate this synergy.

\section{CONCLUSIONS}

In summary, we have shown that the functionalization of water-soluble polymers by a bisurea sticker $\left(\mathrm{U}_{2}\right)$, confers an unexpected and reversible thermoresponsive behavior to $\operatorname{poly}(N, N$ dimethylacrylamide) (PDMAc), poly(N-4-acryloylmorpholine) (PNAM), poly(2hydroxethylyacrylate) (PHEA), polyacrylamide (PAM) and poly(acrylic acid) (PAA) homopolymers, for which no LCST-type behavior in water below $100{ }^{\circ} \mathrm{C}$ has been described before. ${ }^{1-5,7,18}$ Comparison with octadecyl-terminated reference polymers clearly evidenced that the bisurea sticker was responsible for this behavior. Both the octadecyl and the bisurea stickers drive the polymers to self-assemble in water, however, the structure of the assemblies is inherently different. While for the octadecyl sticker, spherical micelles are formed and no cloud point is observed, the bisurea-sticker drives the polymers to form bottlebrush-type cylindrical 
micelles $^{11}$, of which the specific spatial arrangement must be responsible for the observed temperature-dependent solubility, presumably by the hydrophobic effect. Moreover, DSC and FTIR analyses revealed an endothermic transition related to the dissociation of the H-bonds between bisurea moieties. The combined results showed that this endothermic transition and the visually observed cloud point are two distinct phenomena that are inversely dependent on the $M_{\mathrm{n}}$ of PDMAc: whereas the cloud point temperature increases with increasing $M_{\mathrm{n}}$ of the PDMAc, the endothermic transition temperature ( $\left.\mathrm{TT}_{\text {nanoDSc }}\right)$, i.e. the stability of the H-bonds, decreased with increasing $M_{\mathrm{n}}$. Finally, we have also shown that the cloud point cannot only be tuned by synthesizing polymers of distinct $M_{\mathrm{n}}$, but also by mixing PDMAc- $\mathrm{U}_{2}$ polymers of different molar masses.

Most of the former strategies that allow conferring tunable thermoresponsiveness to watersoluble polymers rely on the insertion of hydrophobic and/or functional comonomers within the polymer chain, for instance by statistical copolymerization strategies. ${ }^{1,7,8,16}$ Compared to these former strategies, where several comomoner units are inserted in the polymer structure changing thereby the intrinsic properties of the polymer, the strategy devised in this work relies on the addition of a single bisurea unit to the chain end of polymers conferring them a reversible temperature-responsiveness, while preserving the chemical structure of the polymer. This property is a general feature of bisurea-functionalized hydrophilic polymers and can be tuned as developed above. Future developments are directed towards the application of these thermoresponsive supramolecular assemblies in catalysis and in the biomedical field.

\section{SUPPORTING MATERIAL}

Supporting Information. Details on the characterization techniques, and additional synthesis and characterization data are provided in the Supporting Information file.

\section{ACKNOWLEDGMENT}

The authors thank the French Agence Nationale de la Recherche (PISAForFilms project, ANR17 CE09-0031-01). They also thank Olivier Colombani and Dominique Hourdet for helpful discussions. 


\section{References}

${ }^{1}$ Zhao, C.; Ma, Z.; Zhu, X.X. Rational design of thermoresponsive polymers in aqueous solutions: A thermodynamics map. Progr. Polym Sci, 2019, 90, 269.

${ }^{2}$ Doberenz, F.; Zeng, K.; Willems, C.; Zhang, K.; Groth, T. Thermoresponsive polymers and their biomedical application in tissue engineering - a review. J. Mat. Chem. B 2020, 8(4), 607.

3 Sponchioni, M.; Capasso Palmiero, U.; Moscatelli, D. Thermo-responsive polymers: Applications of smart materials in drug delivery and tissue engineering. Mat. Sci. Eng. CMater. 2019, 102, 589.

${ }^{4}$ Kim, Y.-J.; Matsunaga, Y. T. Thermo-responsive polymers and their application as smart biomaterials. J. Mat. Chem. B 2017, 5(23), 4307.

${ }^{5}$ Roy, D.; Brooks, W. L. A.; Sumerlin, B. S. New directions in thermoresponsive polymers. Chem. Soc. Rev. 2013, 42(17), 7214.

${ }^{6}$ Aseyev, V.; Tenhu, H.; Winnik, F. M. Non-ionic thermoresponsive polymers in water. Advances in Polymer Science 2011, 242(Self Organized Nanostructures of Amphiphilic Block Copolymers II), 29.

${ }^{7}$ Yin, X.; Stöver, H. D. D. Probing the influence of polymer architecture on liquid-liquid phase transitions of aqueous poly( $N, N$-dimethylacrylamide) copolymer solutions. Macromolecules 2005, 38, 2109.

8 Nichifor, M.; Zhu, X.X. Copolymers of $N$-alkylacrylamides and styrene as new thermosensitive materials. Polymer 2003, 44, 3053.

${ }^{9}$ Kujawa, P.; Segui, F.; Shaban, S.; Diab, C.; Okada, Y.; Tanaka, F.; Winnik, F. M. Impact of End-Group Association and Main-Chain Hydration on the Thermosensitive Properties of Hydrophobically Modified Telechelic Poly( $N$-isopropylacrylamides) in Water. Macromolecules 2006, 39, 341.

${ }^{10}$ Fuchise, K.; Kakuchi, R.; Lin, S.-T.; Sakai, R.; Sato, S.-I.; Satoh, T.; Chen, W.-C.; Kakuchi, T. Control of thermoresponsive property of urea end-functionalized $\operatorname{poly}(\mathrm{N}-$ isopropylacrylamide) based on the hydrogen bond-assisted self-assembly in water. J. Polym. Sci.: Part A: Polym. Chem., 2009, 47, 6259.

${ }^{11}$ Gruschwitz, F. V. ; Klein, T. ; Catrouillet, S. ;. Brendel, J. C. Supramolecular polymer bottlebrushes. Chem. Commun, 2020, 56, 5079.

${ }^{12}$ Mellot, G.; Guigner, J.-M.; Jestin, J.; Bouteiller, L.; Stoffelbach, F.; Rieger, J. BisureaFunctionalized RAFT Agent: A Straightforward and Versatile Tool toward the Preparation of Supramolecular Cylindrical Nanostructures in Water. Macromolecules 2018, 51, 10214.

${ }^{13}$ Chebotareva, N.; Bomans, P.H.H.; Frederik, P.M.; Sommerdijk, N. A. J. M.; Sijbesma, R. P. Morphological control and molecular recognition by bis-urea hydrogen bonding in micelles of amphiphilic tri-block copolymers. Chem. Commun. 2005, 4967.

${ }^{14}$ Catrouillet, S.; Bouteiller, L.; Nicol, E.; Nicolai, T.; Pensec, S.; Jacquette, B.; Le Bohec, M.; Colombani, O. Self-Assembly and Critical Solubility Temperature of Supramolecular Polystyrene Bottle-Brushes in Cyclohexane. Macromolecules 2015, 48, 1364.

15 Mellot, G.; Guigner, J.-M.; Bouteiller, L.; Stoffelbach, F.; Rieger, J. Templated-PISA: Driving Polymerization-Induced Self-Assembly towards the Fibre Morphology. Angew. Chem. 2019, 58, 3173. 
${ }^{16}$ Mun, G. A.; Nurkeeva, Z. S.; Beissegul, A. B.; Dubolazov, A. V.; Urkimbaeva, P. I.; Park, K.; Khutoryanskiy, V. V. Temperature-responsive water-soluble copolymers based on 2hydroxyethyl acrylate and butyl acrylate. Macromol. Chem. Phys. 2007, $208,979$.

${ }^{17}$ D’Agosto, F.; Hughes, R.; Charreyre, M.-T.; Pichot, C.; Gilbert, R. G. Molecular Weight and Functional End Group Control by RAFT Polymerization of a Bisubstituted Acrylamide Derivative. Macromolecules 2003, 36, 621.

${ }^{18}$ Fischer, F.; Zufferey, D.; Tahoces, R. Lower critical solution temperature in superheated water: the highest in the poly $(N, N$-dialkylacrylamide) series. Polym. Int. 2011, 60, 1259.

${ }^{19}$ Gelfi, C.; de Besi, P.; Alloni, A.; Righetti, P. G. Investigation of the properties of novel acrylamido monomers by capillary zone electrophoresis. J. Chromatogr. A 1992, 608, 333.

${ }^{20}$ Hideji, T.; Kazuo, H. Structure-toxicity relationship of acrylates and methacrylates. Toxicol. Lett. 1982, 11, 125.

${ }^{21}$ Albarghouthi, M. N.; Buchholz, B. A.; Huiberts, P. J.; Stein, T. M.; Barron, A. E. Poly- $N$ hydroxyethylacrylamide (polyDuramide): a novel, hydrophilic, self-coating polymer matrix for DNA sequencing by capillary electrophoresis. Electrophoresis 2002, 23, 1429.

${ }^{22}$ Swift, T.; Swanson, L.; Geoghegan, M.; Rimmer, S. The pH-responsive behaviour of poly(acrylic acid) in aqueous solution is dependent on molar mass. Soft Matter 2016, 12, 2542.

${ }^{23}$ Gromadzki, D.; Jigounov, A.; Štěpánek, P.; Makuška, R. Synthesis of thermally responsive cylindrical molecular brushes via a combination of nitroxide-mediated radical polymerization and "grafting onto" strategy. Eur. Polym. J. 2010, 46, 804.

${ }^{24}$ Xia, Y.; Yin, X.; Burke, N. A. D.; Stöver, H. D. H. Thermal Response of Narrow-Disperse Poly( $N$-isopropylacrylamide) Prepared by Atom Transfer Radical Polymerization Macromolecules 2005, 38, 5937.

25 Seuring, J.; Agarwal, S. Polymers with upper critical solution temperature in aqueous solution. Macromol. Rapid Commun. 2012, 33, 1898.

${ }^{26}$ Reimhult, E.; Schroffenegger, M.; Lassenberger, A. Design Principles for Thermoresponsive Core-Shell Nanoparticles: Controlling Thermal Transitions by Brush Morphology. Langmuir 2019, 35(22), 7092.

${ }^{27}$ Cremer, P. S. ; Flood, A. H., Gibb, B. C. ; Mobley, D. L. Collaborative routes to clarifying the murky waters of aqueous supramolecular chemistry. Nature Chem. 2018, 10, 8.

${ }^{28}$ Krieg, E.; Bastings, M. M. C.; Besenius, P.; Rybtchinski, B. Supramolecular Polymers in Aqueous Media. Chem. Rev. 2016, 116, 2414.

29 Bellot, M.; Bouteiller, L. Thermodynamic Description of Bis-urea Self-Assembly: Competition between Two Supramolecular Polymers. Langmuir 2008, 24, 14176.

${ }^{30}$ Brunsveld, L.; Folmer, B. J. B.; Meijer, E. W.; Sijbesma, R. P. Supramolecular Polymers. Chem. Rev. 2001, 101, 4071.

${ }^{31}$ Lortie, F.; Boileau, S.; Bouteiller, L. N,N-Disubstituted Ureas: Influence of Substituents on the Formation of Supramolecular Polymers. Chem. Eur. J. 2003, 9, 3008.

${ }^{32}$ Mido, Y. An Infrared Study of the Steric Effects of Alkyl Substituents on the N-H Stretching Absorptions of sym-Dialkylureas. BCSJ 1974, 47, 1833.

${ }^{33}$ Mido, Y.; Fujita, F.; Matsuura, H.; Machida, K. Infrared and Raman spectra of $N$-methyl- $N$ 'alkylureas. Spectrochim. Acta A 1981, 37, 103. 